\title{
RADICAL CARE AND DECOLONIAL FUTURES: CONVERSATIONS ON IDENTITY, HEALTH, AND SPIRITUALITY WITH INDIGENOUS QUEER, TRANS, AND TWO-SPIRIT YOUTH
}

\author{
Jeffrey Ansloos, Deanna Zantingh, Katelyn Ward, \\ Samantha McCormick, and Chutchaya Bloom Siriwattakanon
}

\begin{abstract}
The spirituality and health of Indigenous queer, trans, and two-spirit people occurs within and responds to contexts of extreme colonial violence. However, few studies have examined the relationships among the identity, health, and spirituality of Indigenous queer, trans, and two-spirit youth and their perspectives and activism work in relation to the context of this violence. This study aims to better understand the importance of the connections among identity, health, and spirituality and their role in supporting Indigenous queer, trans, and two-spirit leadership in the enactment of care practices to promote health amidst colonial violence and the worlding of decolonial futures beyond and outside it. Informed by key insights from the grassroots movements and fields of Indigenous feminism, Indigenous queer thought, and radical resurgence, this study brings these insights into conversation, via qualitative interviews with five Indigenous youth activists (18 to 35 years old) from across the part of Turtle Island now known as Canada. Our analysis results in four themes: (1) identity, (2) spirituality, (3) the multidimensional nature of colonial violence, and (4) radical care. We delineate activating practices for decolonial futures, and signal the value of grounded, context-reflective, culturally safe, and intersectional health and youth services. This research demonstrates that spirituality is constitutive of and foundational to the identity and health of Indigenous queer, trans, and two-spirit youth, and shows that health promotion and youth services must address the multidimensional nature of these needs if they are to truly support Indigenous young people, their movements of radical care, and the creation of a decolonial elsewhere marked by belonging, love, self-determinism, responsibility, and joy.
\end{abstract}

Keywords: two-spirit; queer youth; trans youth; Indigenous youth; health and spirituality; Indigenous health

Jeffrey Ansloos PhD (corresponding author) is an Assistant Professor of Indigenous Mental Health and Social Policy, Department of Applied Psychology and Human Development, Ontario Institute for Studies in Education, University of Toronto, 252 Bloor St W, Toronto ON M5S 1V6. Email: jeffrey.ansloos@utoronto.ca

Deanna Zantingh is a PhD student in the Faculty of Theology at the University of St. Michael's College at the University of Toronto, 81 St. Mary St., Toronto ON M5S 1J4.

Email: deanna.zantingh@mail.utoronto.ca 
International Journal of Child, Youth and Family Studies (2021) 12(3/4): 74-103

Katelyn Ward is a $\mathrm{PhD}$ student in Clinical \& Counselling Psychology, Ontario Institute for Studies in Education, University of Toronto, 252 Bloor St W, Toronto ON M5S 1V6.

Email: katelyn.ward@mail.utoronto.ca

Samantha McCormick is a $\mathrm{PhD}$ student in School \& Clinical Child Psychology, Ontario Institute for Studies in Education, University of Toronto, 252 Bloor St W, Toronto ON M5S 1V6. Email: samantha.mccormick@mail.utoronto.ca

Chutchaya Bloom Siriwattakanon holds an MA in Adult Learning and Community Development from the Ontario Institute for Studies in Education at the University of Toronto. Chutchaya works remotely from Bangkok, Thailand for international labour rights organization Verité, 106 Kamias Road, Quezon City, Philippines. Email: bloom.t.k.@gmail.com 
In full metal indigiqueer Oji-Cree poet Joshua Whitehead (2017) intervened in the White heteropatriarchy of the colonial nation state, invoking the language of Indigiqueer "in order to rebeautify and re-member queer Indigeneity" (p. 1). They explained, "For me, to take the word 'Indigenous' and braid it with 'queer' is a new type of worlding" (2018, para. 9). Queer Latinx theorist José Esteban Muñoz (2009) has similarly suggested queerness is a " not yet here' that critically engages pragmatic presentism" requiring a "revival of queer political imagination" (p. 1). The queer political imagination of Indigenous peoples was renewed in the 1980s within twospirit movements and with the guidance of two-spirit teachers (Laing, 2018), and with the development of the fields of Indigenous feminist and queer studies. Both the two-spirit movement and its intersection with Indigenous queer studies have raised the need for considering the health of Indigenous queer, trans, and two-spirit young people who are enduring colonial violence in settler societies like Canada. As Kwagiulth scholar Sarah Hunt (2016) explained, "Two-Spirit health must be understood within the dual context of colonial oppression, which is rooted in heteropatriarchy, and the vibrant resurgence of Two-Spirit peoples' gender roles and sexual identities" (p. 4).

While the two-spirit movement began alongside movements for Indigenous peoples' rights and LGBTQ+ freedoms in the 1980s and 1990s, the movement draws on a broader history of Indigenous epistemologies and ontologies that Indigenous queer studies seeks to articulate (Wilson, 1996, 2008). To be Indigenous and queer has long been deeply interconnected with conceptions of spirituality and health, and a key concern for Indigenous queer studies is how to promote health and spiritual well-being for queer, trans, and two-spirit people, especially youth (Walters et al., 2006).

As Whitehead's $(2017,2020)$ Indigiqueering work signals, Indigenous queer, trans, and twospirit young people are reclaiming these traditions and reframing the health and spirituality of Indigenous queer life in new and important ways. Indigenous queer worldings are replete with the radical possibilities of queer political imagination in which Indigenous peoples exist beyond colonialism, while embodying, and indeed, enriching Indigenous life in the colonial present. As Muñoz (2009) suggested, "the here and now is simply not enough" (p. 96) and Indigenous queer, trans, and two-spirit youth across Turtle Island are worlding an elsewhere.

In this article, we present findings from a qualitative study with a group of Indigenous queer, trans, and two-spirit youth activists from across Canada. Through a thematic analysis of interviews conducted with these young people, our study sought: (a) to deepen understanding of how they are storying their identities as Indigenous and queer people, regarding the realities of colonial histories and colonial presents, as well as anti-colonial futures; and (b) to consider how they are queering concepts of health and spirituality in the context of their activism. Our analysis yielded important themes that nuance our understanding of the multidimensionality of Indigenous queer, trans, and two-spirit identities: the importance of spirituality, radical care, and 
activating practices in navigating colonially entrenched homophobic and transphobic violence, as well as being guided by the ethics of love and sovereignty in worlding anticolonial futures. Our study examines how Indigenous queer, trans, and two-spirit youth are broadening understandings of health and spirituality, and emphasizes their relevance for youth care practice and the promotion of Indigenous queer, trans, and two-spirit youth well-being.

\section{Literature Review}

\section{The Two-Spirit Movement and Indigenous Queer, Trans, and Two-Spirit Youth Identity}

In order to engage meaningfully with Indigenous queer, trans, and two-spirit youth identity, spirituality, and well-being, it is important to contextualize the activism of these young people and its intersection within the broader history of Indigenous queer movements. As Alex Wilson (2008) reminded us, the history of queer Indigenous activism meaningfully intertwines struggles for Indigenous LGBTQ+ rights with traditions of Indigenous epistemologies and ontologies.

The existence of rich queer Indigenous traditions is crucial to acknowledge. Whereas cisheteronormative society regards queer life as something new or evolving, Indigenous queer studies contends that Indigenous nations have understood gender and sexuality in their own terms - namely as fluid, socially and spiritually driven constructs (Fieland et al., 2007). People who expressed fluid gender roles often had respected ceremonial roles as a "spiritual healer" or a "helper" within their communities (Cannon, 1998). However, European colonialism imposed Western gender binarism and White cis-heteropatriarchy on Indigenous communities (Cannon, 1998). Consequentially, Indigenous knowledge systems, ceremonial practices, and cultural identities related to gender and sexuality were pushed into hiding (McLeod, 2017). Despite this, queer Indigenous peoples over the last half-century have resisted the imposed cis-White heteropatriarchy of the colonial nation state. McLeod (2017) stated that in the late 1980s "wherever there was Indigenous activism ... you would find Queer activists participating in the action" (p. 5) and that by the 1990s, queer Indigenous people began to engage in community organizing to achieve the goal of reclaiming their sovereignty by bringing Indigenous knowledges of gender and sexuality from various Nations.

The emergence of the contemporary two-spirit movement in Canada and Indigenous queer advocacy grew out of the 1990 International Gathering of American Indian and First Nations Gays and Lesbians in Winnipeg (Depelteau \& Grioux, 2015). At this gathering, "two-spirit" emerged as an umbrella term for Indigenous gay, lesbian, transgender, bisexual, nonbinary, queer, and trans community members across Turtle Island (North and Central America). Encompassing all aspects of these identities, two-spirit has a special connection to ceremony, responsibilities, and spirituality (Laing, 2018; Wilson, 1996). While there have been tensions regarding how two-spirit identities are to be defined (Depelteau \& Grioux, 2015), two-spirit was not intended to eclipse distinct identities within Indigenous communities. Rather, two-spirit is a term that is "marvellous and malleable" (McLeod, 2017), signifying the ways in which queer and 
Indigenous peoples stand in solidarity against oppressive colonial cis-heteropatriarchy. Rather than "coming out", Wilson (2008) draws the distinction that queer Indigenous people "come in" to be "two-spirit" in order to "be in" places of cultures and histories.

From the 1990s until the present, two-spirit people have been on the front lines of Indigenous and queer advocacy. In line with the burgeoning AIDS crisis during the late 1980s, two-spirit activists established two-spirit- and HIV-focused organizations in Canada to promote and support well-being for people in Indigenous and queer communities; many of these organizations continue to this day (Depelteau \& Grioux, 2015). Throughout the 1990s, a group of two-spirit advocates successfully lobbied the Royal Commission on Aboriginal Peoples ${ }^{1}$ to address discrimination against Indigenous and two-spirit people in Canada (Depelteau \& Grioux, 2015). The rise of two-spirit movements is understood as a reclamation of Indigenous queer people's identities, bodies, spiritualities, health, and land sovereignty (Wilson, 2015).

A growing body of research has examined the important role two-spirit youth have played in reclaiming Indigenous and queer identities. In Dana Wesley's (2015) work, two-spirit youth conceptualize two-spirit as embodied, lived, and as "more a way of moving through the world than a singular self-definition" (p. 2). In interviews conducted by Wesley (2015), two-spirit youth expressed, among other ideas, that their gender was too expansive to be limited to a category, and described "a gray way of life" (p. 52), alluding to holistic ways of being tied to gender, sexuality, and Indigenous identity. These youth suggested that rather than defining "twospirit", it is better to consider what this identity and the community associated with it does to make relations possible. This relationality is exemplified in the work of Marie Laing (2018), who considered how Indigenous queer, trans, and two-spirit youth actively engage in creating community and spaces for themselves. Laing found tremendous diversity in the perceived responsibilities of two-spirit youth. In her study, youth described the importance of Indigenous methodologies, and did this in a variety of ways. For example, some youth described learning words in Indigenous languages, and ceremonial roles from traditional elders and their nation's two-spirit community members. Other two-spirit participants described not knowing traditional roles but creating new roles such as community work and activism.

Two-spirit youth inherit an important role within Indigenous queer community and advocacy work (Laing, 2018; Wesley, 2015; Wilson, 2015). Today, youth often step into the work and spaces created by two-spirit mentors and elders who began the work of building these spaces and communities in the early 1980s. While being two-spirit is political, it is intergenerationally so. Across generations, two-spirit peoples have asserted a dynamic understanding of community, identity, language, land, and place — not merely (as anthropology might frame it) as a cultural practice, but rather, as a political worlding of Indigenous sovereignty.

${ }^{1}$ https://www.bac-lac.gc.ca/eng/discover/aboriginal-heritage/royal-commission-aboriginalpeoples/Pages/introduction.aspx 
International Journal of Child, Youth and Family Studies (2021) 12(3/4): 74-103

\section{Towards Indigenous Queer, Trans, and Two-Spirit Youth Studies}

While Indigenous studies and queer studies are fields with extensively documented advocacy and activism work, Indigenous queer studies constitutes a newer body of research that has emerged from the activism of Indigenous people's resistance to the cis-hetero foundations of settler-colonialism and the worlding of futures rooted in decolonial methodologies. Understanding this field of work and its methodological aims is critical when articulating the distinct ways that Indigenous queer young people are expanding conceptual and theoretical knowledge.

To describe the relationship between queer and Indigenous studies, Qwo-Li Driskill (2010) utilized the metaphor of a Cherokee basket-weaving technique known as "doubleweaving" two separate baskets woven together with a common rim - to describe the union between Indigenous studies and queer studies. In the doubleweave technique, balance is a crucial aspect of design: one basket cannot exist without the support of the other. When Indigenous studies, as the first "basket", focuses on acts of personal and collective sovereignty or self-determination, then the second "basket" - queer-Indigenous activists, movements, and studies — also direct themselves toward this same goal. The connection to queer studies emphasizes that personal and collective sovereignty is inextricably connected to sexual and gender sovereignty and liberation from cis-heteropatriarchy. To carry these two baskets together is to carry a basket full of important gifts and tools that help in working toward self-determination for all Indigenous peoples; gifts that are crucial to the dismantling of colonial gender and sexuality frameworks and the harms they continue to inflict. To be queer and Indigenous is to simultaneously assert Indigenous sovereignty in the most powerful way imaginable: rejecting colonial subjugation and providing access to Indigenous identities, bodies, and spiritualities.

Indigenous feminism also shaped Indigenous queer thinking (Driskill, 2010). Indigenous feminism examines sovereignty and Indigeneity through the critical lenses of gender, sexuality, and identity in decolonization (Driskill, 2010). In contrast to other forms of feminism, Indigenous feminism focuses on the restoration of cultural traditions and self-government (St. Denis, 2007). While Indigenous feminists have consistently called for critiques of colonial patriarchy and its effects upon all aspects of life, they also situate gender violence within the more pressing concerns of their daily lived experience: colonization, racism, and economic disadvantage (St. Denis, 2007). At the core of their aim to decolonize through the restoration of cultural traditions is the call to restore traditional gender relations (Monture-Angus, 1996). As Driskill et al. (2011) noted, "The models of dissent offered by Indigenous feminists support the work of Indigenous GLBTQ2 critics to hold heteropatriarchal legacies accountable to change and thereby support the collective sovereignty of Indigenous people" (pp.18-19). The implications

for queer young people are substantial, as the intersection of not only their gender but also their sexuality interfaces with an often ageist exclusion where adults are frequently prioritzed over young people in various social and community contexts, as well as in the conceptualization and theorization of their own lives, health, and well-being (Laing, 2018). 
Indigenous activist and scholarly work aimed at asserting Indigenous sovereignty must also affirm Indigenous sovereignty over Indigenous bodies and sexualities. As Simpson (2015) asserted, "Indigenous women and Two-Spirit/LGBTQ people have consistently spoken out and organized around the idea of 'sovereign bodies' as a result of the biopolitics (race, gender, and sexuality) of colonialism" (p. 20). For Indigenous peoples, the quest for sovereignty is also a battle about making decisions for and about our bodies (Arvin et al., 2013). As a whole, queer Indigenous studies contributes profoundly to transforming Indigenous/Native studies from a field that describes Native peoples to a methodology that critiques colonialism and its modes of description and structures of power (Driskill et al., 2011); therefore, queer Indigenous studies provides a conceptual foundation for Indigenous queer, trans, and two-spirit youth to expand upon.

A key feature of Indigenous queer studies is the analysis of colonial structures of gender and sexuality and the ways in which these structures are rooted in racism and sexism. As Driskill et al. (2011) suggested, "When linked, queer and two-spirit invite critiquing heteronormativity as a colonial project and decolonizing Indigenous knowledges of gender and sexuality as one result of that critique" (p. 3). This is because two spirit is a threat to this hetero and cis-patriarchal system at its core (Hunt \& Holmes, 2015). In the words of one two-spirit youth, "[Two-spirit] prioritizes Indigenous sovereignty in a way that no other term does. I think that's one of the most important things about the term" (Interview quote in Laing, 2018, p. 129). Driskill et al. (2011) also described how, "by disrupting colonially imposed and internalized systems of gender and sexuality, Indigenous queer and two-spirit critiques can move decolonizing movements outside dominant logics and narratives of nation" (p. 19). This is especially significant in that settler colonialism locates Indigenous queer peoples within colonially asserted patriarchy. Two-spirit people defy both coloniality and patriarchy in actively asserting identity in Indigeneity and queerness (Wesley, 2015; Wilson, 2008). While the colonial White heteropatriarchal lens classifies sexuality and race in terms of "normal" and "abnormal", and "White" and "other", queer Indigenous knowledges refuse to be defined through these classifications. Rather, they assert that all Indigenous people are key to their lives and communities and are as diverse as their own diverse Indigenous nations (Driskill et al., 2011). This makes two-spirit people crucial to the success of Indigenous social movements and the actualization of Indigenous sovereignty.

Reclaiming Indigenous sexualities and gender expressions comprises a refusal to allow colonial systems to continue to describe and create "worlds" for Indigenous people to "live" within (Simpson, 2017). Indigenous queer people invite their communities and kinship networks into a collective refusal of the heteronormativity of the colonial system (Driskill et al., 2011). As such, the reclamation of diverse sexualities and gender expressions is a vital mode of collective decolonization that is being led by Indigenous queer leaders. By reimagining kinship networks and asking how family ties invite relationship across difference, Indigenous queer, trans, and two-spirit youth are "rejecting colonial insider/outside binaries" and presenting methods for affirming diversity outside of heterosexual norms (Driskill et al., 2011, p. 20). 
International Journal of Child, Youth and Family Studies (2021) 12(3/4): 74-103

Central to the task of decolonization is the ability to exercise personal and communal agency towards self-determination (Simpson, 2017). For Indigenous queer young people, "body sovereignty is inseparable from sovereignty over our lands and waters. It means that we are reclaiming and returning to traditional understandings of our bodies as connected to Land" (Laing, 2018, p. 58). Two-spirit entails reclaiming all parts of identity, holistically. Laing (2018) also wrote about how two-spirit is a bridge, a unifying term for queer, non-gender-conforming, and non-sexual-identity-conforming Indigenous people to rally around.

In refusing the colonial violence of cis-heteropatriarchy, Indigenous queer leaders are affirming active participation in embodying and creating Indigenous futures for "everyone children, elders, grandparents, parents, aunties, uncles, the ones that are waiting to be born, beautiful people of all genders, sexual orientations and abilities, everyone" (Simpson, 2015, p. 21). They are affirming their role of helping communities move toward collective healing. They are affirming their own sacred ability and innate freedom to make decisions. They are saying yes to the responsibilities of their kinship networks, their clans, their nations, and their lands. They are embracing sovereignty, both individually and collectively, to create worlds outside of colonial domination that will create a good life for everybody - and every body.

\section{Indigenous Queer, Trans, and Two-Spirit Youth Health}

Indigenous queer studies' attention to the politics of body sovereignty is useful in evaluating the current status of Indigenous queer, trans, and two-spirit youth health research. Health research enacted on Indigenous peoples, especially Indigenous queer, trans, and two-spirit youth, has been understood through the lens of colonial conceptualizations of health (Hunt, 2016). Colonial health care systems, in both design and delivery of care, are embedded within the heteropatriarchy, thus creating barriers for queer and two-spirit youth (Hunt, 2016).

Two-spirit youth persistently encounter gaps in services, and health resources that do not adequately allow for a holistic view of health. It is imperative that queer and two-spirit health be conceptualized in relationship with intersecting marginalized identities as well as the broader social determinants of health (Hunt, 2016). In a study that sought to understand the HIV healthcare experiences of two-spirit youth in Toronto, Teengs and Travers (2006) identified migration, unemployment, homelessness, sexual abuse, racism, poverty, and inaccessible services as specific barriers to two-spirit youth health and wellness. From a systemic perspective, such barriers must be understood in the context of erasure, with an understanding that ongoing health inequalities persist in part due to the omission of queer two-spirit voices. Furthermore, where queer-focused social resources are concerned, there is a gap within overall Indigenousfocused services, a gap that also persists within Indigenous community services (Teengs \& Travers, 2006; Wilson, 2008). These gaps lead to poor recognition of two-spirit lives in both Indigenous and non-Indigenous contexts (Hunt, 2015). The narrow perspectives of colonial health practice and the erasure of two-spirit peoples enforce youth displacement, extending colonial violence. 
For many Indigenous queer, trans, and two-spirit youth, the maintenance of health and wellness rests on the foundational elements of advocacy, self-determination, and sovereignty. Despite the debilitation of Indigenous positionality within settler-dominant societies, two-spirit youth continue to take on important roles within the Indigenous and queer community's advocacy work, proactively creating the world that they want it to be (Laing, 2018; Wesley, 2015; Wilson, 2008). Many two-spirit youth report that participating in ceremony is important to them and is a health practice within an Indigenous methodology (Laing, 2018). Queer and twospirit youth are proactive in disrupting narrow views of gender and sexuality, effectively decolonizing these health and wellness domains (Hunt, 2016). Despite the desire to participate in Indigenous ceremony, homophobia and transphobia are barriers to accessing and participating in healing methodologies for many Indigenous queer, trans, and two-spirit youth (Laing, 2018; Wilson, 2008).

The emerging field of Indigenous Health calls for strengths-based and culturally informed approaches to Indigenous health, approaches that draw on cultural connection and continuity. Cultural connectedness is associated with Indigenous youth mental health, beyond other social determinants of health (Snowshoe et al., 2016). This was attested to by Kirmayer and colleagues (2003), who found evidence that building a connection to identity, community integration, and political empowerment can also play an integral role in improving mental wellness for Indigenous youth. In view of this, Hunt (2016) called for a need "to center Indigenous youth perspectives using a strength-based approach" (p. 18). As Hunt suggested, Indigenous queer, trans, and two-spirit youth are actively resisting harmful narratives that problematize Indigenous youth. The resurgence of Indigenous gender roles supports the broader projects of reclamation of cultural knowledge and power, and the rebuilding of community that respects queer life (Hunt \& Holmes, 2015; Simpson, 2012). Wesley (2015) suggested that in resisting pathologizing, queer, trans, and two-spirit youth are not "waiting to be saved, they are theorizing their own lives into futures that center Indigenous concepts of nationhood, traditions, and ceremonies" (p. 43).

Identity, spirituality, and health are linked as core components of understanding Indigenous queer, trans, and two-spirit well-being. Wilson (2008) emphasized that acceptance or affirmation of two-spirit identity is a process of "coming in" and being a valued member of Indigenous communities. Further, the work of Wesley (2015) draws on the need to connect queer identities to language and culture, with some participants asking for the help of community elders and language learners in the translation of the term "two-spirit" into Indigenous languages, or with finding similar terms embedded within their own Indigenous nations. This emphasizes the desire for culturally and spiritually integrated identities and locates these individuals within diverse Indigenous traditions (Laing, 2018). Within the broader scope of Indigenous health literature, many scholars have explored how Indigenous health is best understood as holistic, placing equal emphasis on emotional, physical, mental, and spiritual components (Ansloos, 2017; Lavallee \& Poole, 2010). Within Indigenous health, the importance of community and identity cannot be 
overlooked, as what one person experiences as a community member affects the whole community, and vice versa.

Building a strong positive cultural identity connection is an essential component of Indigenous youth health and life promotion (Wexler, 2014). Wexler discussed how culture promotes "identity, feeling of commitment, and purpose" (p. 73), even when culture is transformed and adapted to match changing and contemporary expressions of that culture. For Indigenous queer, trans, and two-spirit youth, whose experience of colonialism has created cultural dislocation, it is increasingly clear that positive queer and Indigenous identities, and positive and integrative queer-Indigenous identities, are essential for health and life promotion (Laing, 2018; Wilson, 2008). Indeed, to live in the face of colonial violence and go beyond it is an act of resistance that is life affirming for queer, trans, and two-spirit people (Hunt \& Holmes, 2015; Simpson, 2015).

This review has raised several important dimensions relevant to our current study. First, it reveals the activism of Indigenous queer, trans, and two-spirit youth as it occurs in relation to rich two-spirit histories and movements, and elucidates decolonial practices which advance personal and communal self-determination for all Indigenous peoples. Our review also shows that research that calls attention to and amplifies young people's engagement in these practices is needed. The emergence of the field of Indigenous Queer Studies, and the important methodologies and roles it is generating when it comes to fostering the Indigenous political imagination beyond colonialism, are of profound relevance in engaging with Indigenous queer, trans, and two-spirit young people. The contributions that this context can make to the creation of more politically explicated understandings of Indigenous queer youth health, spirituality, identity and activism are significant. Further, the emphasis that Indigenous queer studies places on the process of knowledge production that centres Indigenous queer, trans, and two-spirit people is greatly needed in the areas of health and spirituality. For this reason, our research has focused on amplifying Indigenous queer, trans, and two-spirit youth reflections on their daily practices of resistance in their lived experiences and their worlding of decolonial futures.

\section{Methodology}

\section{Context}

The project that is described here is a component piece of a program of research, led by the first author, entitled Manitou2Manidoo: Conversations with Indigenous Youth Activists, which focuses on conversing with a group of 15 Indigenous young people who are activists identified as leaders in their communities and in their understanding of spirituality, identity, mental health, and community. This program of research was funded by the Social Sciences and Humanities Research Council through the Canada Research Chairs program, and all aspects of the research were approved by research ethics boards. Interviews were conducted between 2019 and 2020 by 
International Journal of Child, Youth and Family Studies (2021) 12(3/4): 74-103

the first author, as well as by a team of researchers under his supervision. Not all of those involved in the research process contributed to this article as authors.

\section{The Current Study}

Five young people who participated in the interviews are expressly involved in taking up matters related to two-spirit, queer, and trans identity, community, and health; four of them explicitly identified themselves as two-spirit, trans, or queer people. A fifth participant explicitly made the connection between their identity, sexuality, spirituality, health, and work. For the purposes of the findings presented in this article, herein referred to as the study, we, the research team, are drawing on an analysis of these five interviews only, as we seek to highlight the voices and perspectives of those with lived experience of identity and activism within two-spirit, queer, and trans communities.

\section{Research Team Positionality}

The research team, as well as this group of authors, includes queer, trans, two-spirit, Indigenous, Black, and racialized people, as well as some who identify as White and as settlers. At the time of submission of this article, all research team members were residing in Tkaranto, Turtle Island, and ranged in age from 20 to 36, variably self-identifying as young adults, youth, and those who are no longer youth. We are a collective of people that includes mad, disabled, and neurodivergent folks. Some of us are religious, spiritual, and traditional, while others are none of these. We are all engaged in longstanding community work with Indigenous people, and are committed to anti-oppressive, anti-colonial, queer, and feminist practices. Our biases are many, and our commitments diverse, but we are aligned in reflecting on the limitations and privileges of our positionality as folks who have access to institutional power and research resourcing, and who have been socialized, and indeed colonized, by disciplinary perspectives. We contest the colonizing forces of education, psychology, religious studies, child and youth studies, and health sciences. Our commitment is to attend to the effects of bias and power imbalances, to include forms of accountability in research through consensus-based reconciliation approaches, and, as researchers who use participatory practices, to engage in feedback and input, and contribute to knowledge creation.

\section{Participants}

In accordance with our informed consent process, participants did not need to provide any descriptive or demographic information to participate in this study provided that they were Indigenous persons between 18 and 35 years old. Participants were recruited through community peer-referent sampling. Consideration was given during sampling to recruitment of activists doing work within Indigenous queer and trans communities. Disclosure of participant's gender, sexuality, age, and other demographic information was not solicited; participants volunteered some information without prompting. 
International Journal of Child, Youth and Family Studies (2021) 12(3/4): 74-103

After they were interviewed, all participants were provided with a copy of their transcripts in order to make any changes they wished. All five were invited to anonymize their interview through the creation of a pseudonym or to provide permission for the use of their own name alongside their quotes. While this practice reduces the confidentiality of their contributions, it simultaneously upholds principles of respectful research with Indigenous peoples. Chelsea, Smokii, Kairyn, and Tunchai chose to use their own names; one participant chose to use the pseudonym Oz.

The informed consent process also provided a description of the ways in which the interviews and transcripts could be used in the future so that participants could indicate which uses they consented to. All interview transcriptions drawn on for the purpose of the current article have been granted permission for use in the manner in which they are presented here.

\section{Conceptual Framework}

Our conceptual framework is grounded in two principles. The first asserts that Indigenous queer futures are rich with political imagination: when queer Indigenous activists choose to share their stories, to listen well is to listen for the ways that political imagination takes shape in all aspects of life as they imagine daily resistance to the colonial present through reassertion and reimagining of Indigenous lifeways and futures. Our second principle is that, as youth share their stories, our role is to make evident the various forms and expressions of Indigenous queer, trans, and two-spirit youth political imagination by drawing on important tools and methods used in Indigenous feminism and Indigenous queer scholarship. As Driskill et al. (2011) explained, "Indigenous feminists support sovereignty struggles when they argue that decolonization for Indigenous people will follow declaring sovereignty from the heteropatriarchal politics, economics, and cultures, inherited from colonization" (p. 8). In making evident the futures being worlded by the political imagination of Indigenous queer, trans, and two-spirit youth, our work has been crucially conceptualized through Indigenous feminism's use of methodologies that are "dynamic and multi-faceted" and involve "responding to changing political and social contexts and issues" (St. Denis, 2007, p. 35). Such methodologies produce rich possibilities that continue to redefine Indigenous feminism, and by extension, Indigenous studies, as they dialogue with Indigenous conceptions of gender and Indigenous queer people, theories, and practices. This centres — both within our project and within Indigenous studies — an attention to the experiences, methods, and knowledge production of Indigenous queer people, as well as the often ignored "pain of the doubly and triply marginalized" (Belcourt, 2020, p. 140).

Throughout this study, we attend to the ways in which queer Indigenous young people are making meaning, the language they use to do so, and the dynamic relationship between their lived experiences and structural factors (e.g., colonialism) identified through their interviews. After transcription of the interviews, we engaged in thematic analysis to understand two key domains: (1) how youth narrated their identities as Indigenous and queer people, especially regarding the realities of colonial histories and colonial presents, as well as anti-colonial futures; 
International Journal of Child, Youth and Family Studies (2021) 12(3/4): 74-103

and (2) how these Indigenous young people are queering concepts of health and spirituality in the context of their activism.

\section{Method of Analysis}

Thematic analysis was selected as the method of analysis for a variety of reasons:

- It supports the development of exploratory research through the analysis of commonalities across a research sample;

- It is flexible when generating knowledge from larger sources of qualitative data (e.g., multiple interview transcripts);

- We valued the consensus-based and participatory nature of interpretation, which supports collective approaches to research and includes accountability processes to address bias;

- It affords an opportunity for the involvement of participants in knowledge creation processes through member checking.

Of course, there are also limitations to this method. Given the ways thematic analysis seeks to establish themes across the sample, it risks abstraction and the erasure of nuance and particularity. Procedurally, we utilized Braun and Clarke's (2006) method of thematic analysis, whereby the research team repeatedly read the interviews to form initial impressions and ensure familiarity with them, and then utilized NVivo to code the interviews line-by-line, drawing attention to content relevant to the research questions. To assess inter-rater reliability, codes were examined for differences, which were duly reconciled. Codes were then organized into broader themes through a consensus-based decision-making process. Descriptions of themes were developed and used to annotate conversations that provided salient narrative examples.

Conceptually, then, we have used certain tools to listen to queer Indigenous stories with the understanding that the stories have the power to reshape these very tools. In our conceptual framing, we have tried to honour the methods of queer-Indigenous people who are profoundly transforming Indigenous studies from a field that describes Indigenous people to a method that critiques colonialism and imagines a world beyond it. Indigenous queer activists are worlding a future whose political imagination is bursting into the now, into the space offered within Indigenous feminisms and Indigenous studies. As this political imagination unfolds, it invites everything in its vicinity into its political reimagining of spaces and places where Indigenous bodies, communities, and lands can thrive.

\section{Findings}

Our analysis yielded four themes in our conversations with Indigenous queer, trans, and twospirit youth: (1) identity, (2) spirituality, (3) the multidimensional nature of colonial violence, and (4) radical care and activating practices for decolonial futures. These themes elucidate 
Indigenous young people's perspectives on identity and the intersections of colonial histories, presents, and futures, as well as the ways they are queering concepts of health and spirituality in the context of their work in communities.

\section{Identity}

In conversations with the five young people in our study, identity was taken up in a variety of important ways. Foremost, these young people spoke to the multidimensionality of being queer and trans and emphasized that as Indigenous people this identity is best understood not in individualistic terms but in terms of role and of obligation to community. As Kairyn explained, "Two-spirit is very deeply tied to culture, tied to community, and tied to roles within the community, within the ceremony...". Of course, these roles and responsibilities are not static, but are evolving and sociorelationally constituted. Speaking of their movement between masculine and feminine roles in ceremony, Smokii explained, "I think, in all of this, what I've come to understand my role is as a two-spirit person is that I have the ability to do whatever role is necessary in that moment." Identity in this sense is above all about being in relationship, not only with oneself, but also with the temporal spiritual needs of one's community. Further, Kairyn explained:

The first time I heard that I was two-spirit I was 6 years old and that was my auntie telling me that. She already knew long before I did and that was a sacred thing and she let me know. I realized the power that spirit has. That's where my understanding comes from. It's from my family and from those teachings.

This anecdote demonstrates that identity for Indigenous young people is something that is not merely self-articulated but emerges and is reflected upon in relational contexts which uphold the dignity of two-spirit and, indeed, queer life. It is inappropriate for non-Indigenous people to claim identities such as two-spirit. As Kairyn made clear, this is appropriative violence:

Maybe there's a word in your culture, whatever culture you have, to explain better what you're feeling. Maybe you should look it up, and then leave two-spirit alone. [chuckles] I'm like, "Let us claim that identity because it's ours."

Young people in our study also emphasized the tremendous diversity that exists across and within Indigenous nations, communities, and contexts in articulating two-spirit, queer, and trans identities, and acknowledged the role of Indigenous language in navigating this diversity. According to Kairyn, "If you go into any community and you ask about their language and the history of that language, you'll find so many different definitions for what they believe to be like the equivalent of what two-spirit is."

The five young people in our study, who themselves diversely identified as trans, queer, and two-spirit, emphasized the importance for them of reawakening their linguistic connections to culture, and how that process supported the resurgence of Indigenous notions of sexual and 
gender identity, which differ from contemporary White homonormative perspectives. As Kairyn explained:

I was coming out to my cousin and my aunt was there and I said I'm gay. She said you're not gay, you're two-spirit. I said, "What is that?" She said, "My boy, you're so feminine and you're so much like your mom." She said, "That second spirit you have, that's your mom's spirit. It's inside of you and it's with you all the time. That's why you remind us so much of her. That's energy," she said, "and that's power." That's another example of just like learning about spirit and learning how that drives you and how that completes you as a person and how even though you pass on, that spirit doesn't just go, it doesn't just disappear. It stays in this realm.

In Kairyn's account, there is a clear departure from framing sexuality in terms of "coming out as gay" towards a culturally situated notion of gender and spirituality, which centres their life within a spiritual identity and intergenerational connection. Similarly, Smokii was deeply concerned with reframing queer and trans lived experiences of connection to community, from the tropes of developmental milestones or rites of passage of "coming out" to affirmations of community responsibility to create safety for and take care of diverse Indigenous life:

I just want to abolish the idea that we need to have this coming out in order to like to start our lives as who we are because we really don't. I almost envision a society of, especially for my community, the Indigenous community, just having young people naturally take up those roles like they used to and having the community recognize at a very young age, these unique people — and protecting them and fighting for them and fostering them like how they used to.

Indigenous queer and trans young people often experience a conflict of identity, which stems from alienation from their own community, experiences of homophobia and transphobia within and beyond their community, and a positioning of identity as non-intersectional. Speaking of their early teens, Oz explained:

I still didn't know what it meant to be an Indigenous person, because I was also very conflicted with my Indigeneity and my sexuality and my gender, because I was told at a young age that I couldn't be two-spirit ... I couldn't be gay and I couldn't be Native.

Coming out as a process is often situated within an identity politic that invisibilizes Indigenous young people's intersectional identities as racialized people. In conversations with Indigenous queer and trans young people, connection to identity is work that requires intentional reawakening and reconstituting of cultural traditions, language, and community relations. As Smokii has alternatively suggested, "The work that I do is on coming-home narratives." 
International Journal of Child, Youth and Family Studies (2021) 12(3/4): 74-103

\section{Spirituality}

The five Indigenous young people included in this study discussed matters of spirituality in several important ways. First, these young people emphasized that cultural resurgence was critical to their understanding and experience of spirituality. As Chelsea explained:

To be able to interact with communities and continue to have capacity, is to really be looking within and having that sense of cultural grounding. I see that that is one thing that I really try to intentionally focus on in different places and engagements. That's what keeps me calm and that's what keeps me going, is embodying cultural grounding.

Of course, this emphasis on cultural grounding, while important in and of itself, doesn't occur in a sociohistorical vacuum. Young people in our study were acutely aware of the ways that cultural connection and resurgence is a tactical response to the impositions of colonialism. As Chelsea explained:

I'm learning my language, because I had family on both sides up until my grandparents and my parent on one side of the family attended residential school. That had a huge impact on the language and connection to our culture not being passed on.

In order to understand the central importance of resurgence work for Indigenous queer, trans, and two-spirit young people, it is essential to understand intergenerational experiences of colonialism. Smokii explained that, "My mom, who is Indigenous, had gone to college and learned about residential schools and learned about some things and then came home and pulled me out of catechism and was like, "We're not doing that any more." This refusal, or at times in conversations with other young people, rejection or reconstitution, of colonially imposed religion was a key dynamic of Indigenous resurgence processes.

We also see in our conversations with young people that this complex relationship to colonialism has had pervasive effects within Indigenous communities' spiritual traditions and practices, which have been and are being shaped by colonial ideologies. As Oz suggested, "Questions around spirituality for so many people are so closely tied to the history of colonialism. Some communities the closer you get to ceremony and spirituality, the closer you also encounter issues like homophobia." So, for many young people, in as much as resurgence is a move away from colonialism, it is also a practice of resisting the internalization of colonialism within Indigenous communities - a type of decolonizing spiritual practice.

Another important contribution of young people in this study is their nuanced theorizing of spirituality from their own perspectives and lived experience. Importantly, these perspectives were offered from the vantage point that spirituality is lived and is a pathway, journey, and 
process. As Kairyn said, "I think that at the core of who I am that spirit is always growing and that spirit is constantly looking for things." Or, as Smokii suggested:

The best part about spirituality is that it's a constant learning and that there's never ... You never get a $\mathrm{PhD}$ in Spirit. Even elders are learning right up to the end, and after too, some teachings say a year, or others 4 years, until someone does their learning on that side too, to become a helper, an ancestor. I think we're always learning and that's the other piece that I love so much about it is that it continues.

This pedagogical positioning of queer, trans, and two-spirit spirituality is in itself a philosophical shift beyond the anthropological encoding of spirituality as a particular religious dogma or ideological position that exists beyond lived experience. Rather, young people's intervention here helps to reframe assertions about spirituality — indeed, about living — as dynamic: they are subject to change and revision.

Indigenous queer, trans, and two-spirit young people also brought to bear the language of relationality as a primary framework in describing their understanding of spirituality. Beginning with the subjective, young people emphasized the importance to spirituality of integrated identity and belonging. They emphasized that spirituality was about self-awareness, and connection of themselves and their own spirit to broader relations. As Kairyn indicated:

I oftentimes look at my spirit as fire and ice. I use that analogy a lot because it's something that really resonates with me and helps me understand it better myself. I think anybody you ask they're going to have a different answer for what their spirit is and what that understanding of spirit is going to mean in their life. For me personally it's this drive, it's this fire inside of me that makes me who I am. Sometimes it's dull and it's quite little. It's like a little flicker but sometimes it's a forest fire and no matter what I'm always feeding that spirit.

Here Kairyn is making an important assertion about concepts of personhood, which includes a spiritual life. As Smokii suggested, attending to this dynamic is a type of reciprocity where "we care for the thing that is caring for us. Whatever it is, it's that consistent balance." It is from this place of recognition of the spiritual life that Indigenous queer, trans, and two-spirit young people make the suggestion that relationality extends outwards and intersubjectively. Chelsea explained:

To be connected to the people around me ... It's very decentralized in that way. It's not only thinking about the self and the individual in relation to the community and creator, or the universe or source, but it's to be conscious of my own life, and then also what's around me, and how the work, and the things that I do, and how that has a connection to my relations. 
In this sense, spirituality is also deeply connected to other relations, including family and community. Indigenous queer, trans, and two-spirit young people drew attention to the importance of intergenerational expressions of spirituality. Smokii explained that this relational and intergenerational connection is life sustaining:

I do not think I would be here. I have no doubt that I would not be here, had I not been able to start walking this road, and been gifted with the teachers that I had and been able to see it and really witness it.

This intergenerational relationality is multidirectional, as Kairyn shared: "You can learn from a 2-year-old and you can learn from a 90-year-old. We're all just trying to learn about each other, and so I just want to make it easier for people to do that."

In many conversations with young people, this relational dimension of spirituality also extended from and beyond human relations, towards land-based relations. As Chelsea explained:

I have that connection mostly to the land that I'm on. Into this territory because a lot of my family lives here, and so that's where I think of where my spirit resides and where my spirit is enmeshed to the earth's energy. In a greater sense, I'm also connected to the spirit of Indigenous people across Turtle Island and across Canada.

This is a vital linking of personal spirituality to the spirituality of land - both as a place and space. As young people expressed it, land is a material territory, where one resides, and has embodied connection. Land is also immaterial and connects young people to broader spiritual stories of beginning, such as creation stories of Turtle Island.

A spiritual relationship to place and space holds the potential to shape emotions and affective relations, even in ways that might be described as healing. As Smokii explained:

I was like two days sober. I got sober in Winnipeg. It was quite the time. I went, "Oh, I should smudge by the water. I should smudge." Because I had been taught on Coast Salish territories to do this. I sat by the Great Lakes, which, I mean, I go ... If you want to feel spirit, go sit by that because I just went, "Oh, they mean great!" I had never been around them and I grew up in the Rocky Mountains. It was the first time I understood what people feel when they come here because it was like, "Oh, this is something. This is a different energy."

These place-based and spatial relations are generative, expansive, and reciprocate relationally and affectively. As Smokii elaborated:

Then also the land [is] sustaining us. I think I made that comment about a chair and that's standing out to me recently because it's like, well, would we call the chair holding you up "love"? I don't know, but at the same time, maybe. Now that 
International Journal of Child, Youth and Family Studies (2021) 12(3/4): 74-103

I'm thinking about this because I think in these ways, the ways we can start thinking about how big it is. Even just spending time witnessing the buds because it's springtime right now, so I'm like, "The world is love. This is so beautiful."

Young people like Smokii address the radically transformative possibilities of land-based relations in seemingly inconspicuous places. They reveal that a spirituality of everyday life is possible when attending closely to the relationality of place and space, even indirectly, with objects and materials that come from the land. As Kairyn suggested:

From when I was really young, we were always taught that everything has spirit, everything. Look at that rock, look at that tree. Everything has a spirit. You have a spirit. You are spirit. I think that goes for most Indigenous young people who are growing up. You're always hearing that everything has a spirit.

Rather than following the descriptive impulse driving anthropological studies of Indigenous spirituality, the conversations about spirituality with young people in our study focused on the ways that relationality with land, spirit, ancestors, and nonhuman relations helped them position themselves in the world and emboldened them to move through it with greater consciousness. As Smokii reflected, "I always went to the water, always was in the ocean and these bigger things, bigger than me." Or as Oz suggested, spirituality is "kind of like 'the force' where everyone is connected, in a sense. And if you do something over here, that it's going to have a ripple effect over there." Perhaps most profound was the way that queer, trans, and two-spirit youth described spirituality in language that conferred dignity upon one another.

Speaking of their own lived experience and coming to terms with spirituality as a two-spirit person, Kairyn said:

Let me give you this teaching — this gift, of your grandma's grandma and your great grandma's grandma, and this idea that they had that was so beautiful within our community. Let me tell you why you're not only not a mistake, you are sacred, and you are so valuable. In order for our people to continue you are a huge key component of that. Your ancestors are standing right behind you and you have all of that power behind you.

Indeed, queer, trans, and two-spirit young people demonstrate how their spirituality is an enlivening and nourishing presence in their own lives, and in the places and spaces of their lives.

\section{The Multidimensional Nature of Colonial Violence}

In discussing their identity and spirituality, young people described the ways their lived experience included dimensions of colonial violence, both historical and present-day. In their experience, colonial violence intersected with the discrimination they had encountered as sexually diverse and gender-diverse people in ways that signal the intergenerational effects of 
residential schools and the imposition of homophobic and transphobic ideologies upon Indigenous communities. As Oz explained:

You can't dance. You can't sing, you can't drum, you can't wear regalia. You can't do any of that, any of that, you can't come to ceremony, you can't come to lodge. Because you're gay, because my family tells me that that's wrong. And that if you want to come to ceremony, and if you want to come to pow wow, then you have to hide that part of yourself.

As Oz's words make clear, colonialism produces a relational alienation from culture and community, which, in this context, is based on gender or sexual orientation.

Young people also described experiences of colonial violence through the marginalizing and invisibilizing force of hetero- and cis-normative attitudes. Kairyn explained:

It's confusing a lot of people who aren't in the community because White cisgender people who are heterosexual, who don't know anything about the community will come in and say, "Oh, it's a trans woman. She's a lesbian because she has a boyfriend", even though that's not how it works. The people just don't understand sex, gender, sexual orientation. It's just this big scary world that they just don't have any desire to learn about or they don't take the time to educate themselves on it.

Like Kairyn, other young people described multiple experiences of stringent reinforcing of gender binaries and heterosexuality as normative, despite their own presence and differing lived experience; often they felt forced to hide or disappear. Oz elaborated:

... like as an Indigenous person, as somebody who's brown enough to be racialized by other people, and somebody who is queer and sometimes feminine, because I'm also trans fluid, uh, gender fluid, and, and it's just — it's just really difficult because I can't always be who I want to be in this - all the time. And and I wish I could. And if more people were aware, then more people wouldn't fall through the cracks. And more people can care and more people, again, can show that kindness.

Queer, trans, and two-spirit young people make clear that often experiences of transphobic and homophobic violence, as well as cis-heteronormativity, are meaningfully connected to racism, and a distinctive expression of White supremacist violence. As Kairyn explained:

You find that the world isn't really made for you sometimes and you face a lot of racism, a lot of systemic racism.... It's just a bunch of White people driving trucks with aggression and a lot of Gerald Stanleys running around who just like they see a brown face and they just get angry. 
International Journal of Child, Youth and Family Studies (2021) 12(3/4): 74-103

As Kairyn made clear, White settler-colonial rage marks Indigenous lives and the bodies of queer, trans, and two-spirit young people for extinction. In referencing Gerald Stanley, who was acquitted for the 2017 murder of 22-year-old Colten Boushie (Barrera, 2018), Kairyn reminded us that violence motivated by anti-Indigenous prejudice is not only material, but is institutional, systemic, and structural: it pervades aspects of the justice system, education, and health care. As Chelsea shared, "There's a lot of systems that need healing because of colonialism, and colonization is a structure, not an event."

\section{Radical Care Practices and Activating Decolonial Futures}

Queer, trans, and two-spirit young people in our study were selected in part for their leadership as Indigenous activists and the ways that they are imagining and organizing change in their communities. This lived experience is reflected in a key theme that emerged in our conversations with these young people: we noted a range of radical care practices that activate decolonial futures and enliven their sense of vitality even in the midst of colonial occupation.

In terms of radical care, queer, trans, and two-spirit young people recognized the dynamic ways that care practices not only preserve life but convey value and help people to reconnect spiritually. As Smokii put it, “Those spaces of community care, that's what I think Spirit gives. Again, not just human physical community care, but that knowing that I'm okay, and knowing that I'm here, and that I'm taken care of is so deeply important." Their expansive understanding of care practices indicates the radical view of care held by these young people.

Notably, the young people in our study were highly active in the areas of mental health and wellness promotion; however, their notions of mental health care disrupt the colonial notion of mental health management, especially with regard to professionalization and biomedicalization. As Kairyn described it: "We have a Knowledge Keepers Council complete with seven Knowledge Keepers in the community who can provide counselling services to Indigenous youth, two-spirit youth." Who provides counselling supports for queer, trans, and two-spirit young people matters deeply, as these knowledge keepers are often important interlockers of cultural knowledge and community connection. Later Kairyn also reiterated the importance of elders in radical care:

Yeah, my auntie, she was a, a two-spirit person and an elder in her community. She passed away, last year unfortunately, but she's a, she knew right — right away that I was also different, that I was also one, "one of us".

There is a way in which this linking to two-spirit elders activates a particular sense of community and possibility for Indigenous queer, trans, and two-spirit young people. This grounded sense of well-being is also deeply connected to spirituality. As Tunchai explained, "The process of colonization has entirely disconnected Indigenous people from that place of spirit. In order for anybody to heal, and any communities to heal, any Indigenous young people 
to heal — they need to call back or reconnect with that spirit." Similarly, Kairyn explained about their work with young people:

We just want you to blossom and to take on that leadership and to own your life. You won't believe the amount of young people who resonate with that and how many people feel like wow this makes sense. Wow, I'm not alone. Then they start realizing those things that are inside of them, all of these questions that they have growing up they realize that none of that is like bad. That's all exciting. It has so much cultural significance tied behind it. That's how we save lives, their mental health, their well-being, all of these things. They start to fall into line because they start seeing it as necessary changes within their lives rather than things that need to be pushed away or things that need to be hidden or stifled. We can start celebrating them rather than simply tolerating them. I think that's the effect that teaching of spirit and that understanding of spirit is having on young people.

Another key feature of radical care practices that we noted in our conversations with young people was the central importance of opportunities for cultural connection, grounding, and relationship in the promotion of mental health and well-being. Discussions of cultural ceremonies, practices, and spiritual teachings were rarely framed in instrumentalizing language, but rather in stories and lived experiences. As Smokii explained:

"There's a movement in Vancouver that's the Culture Saves Lives is what they say. There's a downtown east side where they're talking about how do we get lodges into recovery houses, and detoxes, and this kind of thing. I super believe we need it everywhere ... When you come into the lodge, I often talk about this when you start opening up to it. It's very much about ourselves at first. I need healing. I'm struggling. Please help me. I needed that. I needed people to help me. I needed that unconditional love and support. Once that is happening, once I've been gifted with that, and I start to be able to stand on my own in that, my responsibility is to continue that cycle and create that space and then really be listening and learning.

Grounded and relational connection to cultural ceremonies, practices, and spiritual teachings is not merely about consuming a particular form of care, but about activating communities of care.

The promotion of care is not linked only to the psychotherapeutic. As Oz suggested, "I think about wellness in that way and I think about wellness in a physical sense: Have I connected to Mother Earth recently? Have I connected to Mother Earth today? Felt the sun, felt the ground, been outside, seen other people?" Attending to land-based relations is a key feature of queer and trans wellness promotion.

Care can look different for different people. As Oz explained, 'It's not just ceremonies and it's not just lodge. For some people it's writing, for some people that ceremony is athletics, it's, 
it's, uh, it's governance. It's — it's — it's studying, it's academic, it's art." Similarly, Kairyn suggested, "Healthy relationships looks like basic needs being met. That means housing. That means love. That means purpose. That means education. That's what I would define as wellbeing as having all of those needs met."

Sexual health promotion was another key activating practice of radical care for Indigenous queer, trans, and two-spirit young people. All five participants were involved in providing training, advocacy, and peer education around sexual health and harm reduction. As Kairyn explained, "We make sure that we are a hub for resources for mental health and sexual health", and as $\mathrm{Oz}$ emphasized, this work is to help young people "empower themselves as a community".

Empowerment is an important aspect of the ways that these radical care practices activated young people to begin organizing and advocating for themselves and other young people. All five Indigenous young people in our study actively situated themselves and their work as engaged in social movements. As Chelsea described it, this is a "decolonial education", which is about "figuring out the ways in which both Indigenous and non-Indigenous people can learn what their individual roles are in dismantling those systems and creating and holding space for Indigenous youth." For the young people in our study, this activation took the form of direct action, mutual aid, service on community boards, and vocational service to organizations.

Woven throughout the stories of the five Indigenous young people in our study was a clear set of ethical principles that, when embodied, activated much of their mobilizing work in communities. As Smokii explained, "The goal is to do everything with a gentle loving nature because that's how people learn." Similarly, Tunchai reflected, "That connection to spirit has saved me, and I know it's what can save communities - connecting young people to that sense of love, belonging." Joy also serves a similar purpose, as Chelsea reflected: "We're always laughing, and that's what really brings that spirit into the space." While the work of these Indigenous queer, trans, and two-spirit young people was complex and the challenges of the violence they faced were relentless, it is striking that they spoke of their work in tender and responsible terms. As Oz said, "It's the importance of trying to walk gently — being mindful of others, being mindful of your words and your actions and the impact they have on others, and even in your inactions."

\section{Discussion}

In this study, by focusing on what we learned from these five young people, we have sought to better understand how Indigenous queer, trans, and two-spirit youth are making sense of questions of identity, health, and spirituality within a particular structural reality - and beyond the colonial violence that it embodies. As de Finney (2014) suggested of Indigenous girlhoods, the young people in our study were navigating challenges and creating vital community and care practices both within and beyond "the shadow of empire" (p. 8). 
At the intersection of identity, our study makes clear that Indigenous queer, trans, and twospirit young people are diverse in understanding and articulating identity, but they share in situating sexual and gender identity as a communal, relational, and spiritual role and responsibility. This is consistent with Walters et al.'s (2006) findings that highlighted the interconnectedness of being Indigenous and queer with spirituality and wellness. Queer, trans, and two-spirit young people in our study also engaged in explicit resistance to White homonormative framings of sexuality and gender, and instead grounded their understanding of identity within cultural, linguistic, and social and place-based relations. Laing (2018) has similarly emphasized that two-spirit youth are active in resisting White supremacy and cisheteronormativity by claiming and living connected cultural and sexual identities. Our study elaborates on this by emphasizing that there are significant challenges associated with navigating identity development in the context of existing forms of structural violence, including colonialism, racism, homophobia, transphobia, and patriarchy.

The contributions of the queer, trans, and two-spirit young people in our study evinced an understanding of spirituality closely linked to their beliefs about the importance of cultural resurgence and Indigenous self-determinism. Their stories suggest that the best way to understand spirituality is not through anthropological means, but through grounded and lived-in, place-based, spatial and relational means. This is an important contribution because it conceptually challenges the impulse behind much of anthropological and religious studies, and the dominant forms of Western Christian practice that shape the realms of health, politics, religion, and education in which Indigenous youth live, and in relation to which they are worlding an elsewhere. In their contribution to queer Indigenous studies, these five young people follow Leanne Simpson (2015) in offering critiques and conceptions of spirituality that have important potential for understanding the nature of colonial cis-heteropatriarchy in its many forms. The theoretical views held by Indigenous queer, trans, and two-spirit youth, together with their lived experiences, provide critical methodologies with which to disrupt the cisheteronormativity of the colonial state, to disengage from colonial modes of thought, and "to rebalance Indigenous communities" (Driskill et al., 2011, p. 18). The queer, trans, and two-spirit young people in our study showed that although colonialism has had a profound negative impact on Indigenous young people's relationship to spirituality, it is also the case that cultural identity development and resurgence are linked to its reclamation.

Decolonization is spiritual work. And while spirituality as a discursive framework carries the baggage of the harms of colonial religious interventionism, for the young people in our study, spirituality and the relationality that they enact through everyday commitments are lifepromoting and pedagogical, and foster self-determination. This is an important finding because it means that Indigenous youth wellness promotion needs to begin from the presupposition that spirituality, understood in place-based and relational ways, is a mode of resilience and empowerment. As Simpson (2017) suggested, to decolonize is to be rooted in grounded normativity and Indigenous self-determinism, and in being aware of — and growing in — one's 
ability to exercise personal and communal agency. The people in our study enact a queer imagination in spirituality, which sustains them in the ever-present realities of colonialism while also helping them to grow, learn, and world decolonial elsewheres.

On the topic of colonialism, our study also shows the profound and far-reaching nature and effects of multidimensional colonial violence. Hunt (2016) showed that colonialism is a structural driver of inequality and a negative social determinant of health, and consistently, we saw in our study that for these five young people, the violence of colonialism was pervasive in everyday interpersonal, communal, material, institutional, and systemic ways. Furthermore, these young people made clear that colonialism has produced and continues to produce disruption and dislocation of cultural connection and relations. As Chandler and LaLonde (1998) suggested, this has profound impacts on well-being; as our study has uncovered, this produces psychosocial distress in Indigenous queer, trans, and two-spirit young people's lives. It is not surprising that the violence of colonialism has far-reaching health effects on Indigenous peoples, which include, as Simpson (2012) has demonstrated, the negative influences of rigid gender roles and heteropatriarchy. However, our study reveals that there is concurrently an important dimension of this process in which sexual and gender-based violence intersect with racism. Aligned with Cannon (1998) and McLeod (2017), the five young people in our study affirmed an explicit link between transphobic and homophobic violence, cis-heteronormativity, racism, and White supremacy. As Cannon (1998) indicated, settler colonialism is deeply racist, and this racism is linked to the ways gender and sexuality are regulated and resisted.

We began this study acknowledging Muñoz' (2009) suggestion that queerness is a futuredriven phenomenon or a "not yet here ... insistence on potentiality or concrete possibility for another world" (p. 1). However, our study points to the decolonial elsewheres and worlds that Indigenous queer, trans, and two-spirit youth are prefiguring through various forms and expressions of radical care. Indigenous feminist scholars have long pointed to the need for methods that are inclusive and healing, and show genuine care for all (Green, 2007). Further, Hunt and Holmes (2015) suggested that decolonial practices occur "in the intimate spaces of daily life" (p. 156), particularly in close relationships. Our study makes clear that what makes care practices radical is not wellness promotion but the linking of wellness to undoing the effects of colonialism and prefiguring an anticolonial vitality and livability in the everyday present as a means to usher in a decolonized future world. As Belcourt (2020) suggested, surviving colonialism and life beyond it will require "a radical remaking of the world" (p. 139). In our study, Indigenous queer, trans, and two-spirit young people activated the creation of these livable worlds through an array of practices in mental health promotion and sexual health promotion. In stark contrast to dominant approaches followed in the mainstream, the young people in our study, like the young people in Laing's (2018) and Wesley's (2015) studies, described their mental health and wellness practices in culturally grounded terms that focused on promoting connection to community and cultural teachings. 
Sharing story work, narrative practice, and lived experience is a vital means of activating spirituality and cultural resurgence. Decolonizing care practices are not merely enacted in response to colonialism, but are desire-based. As Tuck (2009) described, this involves "documenting not only the painful elements of social realities but the wisdom and hope" (p. 416). Our study similarly points to the ways in which creative actions of resurgence are worlding community, futurity, and care within and beyond colonialism. These practices are manifold and responsive according to the diverse needs of Indigenous queer, trans, and two-spirit young people.

Radical care practices are meaningfully connected to negotiations of power: radical care practices that pertain to sexuality and gender cannot be examined in isolation from the power dynamics of a person's age, language, society, history, spirituality, and culture, especially when these things have been deeply impacted by colonial occupation. Queer Indigenous political imagination uses approaches based in futurity to unsettle settler colonialism, which includes the unsettling of colonial gender and sexual politics through the assertion of radical care and sovereignty over Indigenous sexuality and gender. In keeping with the methodological practices of decolonizing that emerge from Indigenous feminist scholarship, the young people in our study emphasized the negotiation of power relations through decolonizing and queering education, direct action, community service, and vocational commitments. As such, they enliven a critique of the unlivability of "the world", which as Belcourt (2020) noted, is not a passive concept, but "a unit of power ... [that] harbours the toxins of history" (p. 104); it is a world that can be otherwise, a world that the young people in our study are bringing into being.

Love, joy, belonging, tenderness, responsibility, mindfulness, and sovereignty were central to guiding the imagination and actions of the five young people in our study. The good life is grounded in loving, and that loving, manifested by young people even during the colonial present, is a type of worlding. Like Muñoz's (2009) queer imagination, and Whitehead's (2017) queer "re-membering" of Indigenous relations, this centring of Indigenous social ethics in the work of young people prefigures a powerful decolonial "elsewhere".

\section{Implications for Indigenous Health Promotion and Youth Care}

Our study also offers several important applied contributions to supporting Indigenous youth health promotion. When Indigenous queer, trans, and two-spirit young people spoke about identity, health, spirituality, and culture, it was clear that, for them, these concepts were highly interconnected. This has major implications for health promotion and youth services, contexts in which care practices often fail to integrate these multiple dimensions, and therefore become less relevant. Our study signals the value of grounded, context-reflective, culturally safe, and intersectional health and youth services. When Indigenous queer, trans, and two-spirit young people discussed matters of health, identity, and culture, spirituality was a grounding concept, a foundation in all contexts. Ironically, spirituality is probably the least considered aspect of preparation for health care and youth service providers. Significantly, our study echoes what 
other Indigenous health scholars have argued: that spirituality may be a protective factor in mental health and life promotion (Ansloos, 2017).

Our study also makes clear that there are colonial forms of homophobic and transphobic violence that produce harms and major social inequities in the lives of Indigenous queer, trans, and two-spirit young people. The solutions needed to address these are multisystemic but must include young people and should attend to the solutions that are already being enacted in forms of radical care and decolonial action.

Finally, our study also makes a strong case for the provision of land-based, culturally focused, language engaged, and relationally enhanced youth care and services. It is evident that anti-oppressive work with Indigenous youth needs to meet diverse needs and include material, relational, cultural, and spiritual supports. Further, Indigenous youth work is political work in that it is meaningfully entangled with projects of worlding decolonial futures and resisting multiple forms of violence. Practitioners need to be critically reflective about their own power, to resist the performativity of allyship, and to enact radical care through redistributions of the power and resources that are needed to support Indigenous queer, trans, and two-spirit young people's already emerging decolonial work.

\section{Conclusion}

In conclusion, our study shows how Indigenous queer, trans, and two-spirit youth narrate their stories about their identities, spirituality, and well-being. Their stories demonstrate that identity, spirituality, and radical care practices are critical means by which young people resist and navigate colonial, homophobic, and transphobic violence. Spirituality is constitutive of and foundational to the identity and health of Indigenous queer, trans, and two-spirit youth. Health promotion and youth services must work to address the multidimensional nature of well-being if we are to truly support Indigenous young people, their movements, and their creation of decolonial elsewheres. Grounded in culture, people, and place, young people are forging powerful new ways of living, and lifting each other up in the process. Our findings detail applied implications that can serve to support Indigenous queer, trans, and two-spirit youth in strengthening Indigenous youth health promotion, and youth care and services. The wisdom of these young people is that their political imagination is characterized by invitations towards belonging, expressions of radical care and love, and embodied commitments to self-determinism, communal responsibility, and decolonial joy. 
International Journal of Child, Youth and Family Studies (2021) 12(3/4): 74-103

\section{References}

Ansloos, J. (2017). The medicine of peace: Indigenous youth decolonizing healing and resisting violence. Fernwood Publishing.

Arvin, M., Tuck, E., \& Morrill, A. (2013). Decolonizing feminism: Challenging connections between settler colonialism and heteropatriarchy. Feminist Formations, 25(1), 8-34. doi:10.1353/ff.2013.0006

Barrera, J. (2018, February 14). Gerald Stanley acquittal outrage result of "centuries of oppression," says prominent civil rights lawyer. CBC News. https://www.cbc.ca/news/indigenous/colten-boushie-gerald-stanley-indigenous-justicehistory-1.4532564

Belcourt, B.R. (2020). A history of my brief body. Penguin Random House Canada.

Braun, V., \& Clarke, V. (2006). Using thematic analysis in psychology. Qualitative Research in Psychology, 3(2), 77-101. doi:10.1191/1478088706qp063oa

Cannon, M. (1998). The regulation of First Nations sexuality. Canadian Journal of Native Studies, 18(1), 1-18. http://www3.brandonu.ca/cjns/18.1/cjnsv18no1_pg1-18.pdf

Chandler, M. J., \& Lalonde, C. (1998). Cultural continuity as a hedge against suicide in Canada's First Nations. Transcultural Psychiatry, 35(2), 191-219. doi:10.1177/136346159803500202

De Finney, S. (2014). Under the shadow of empire: Indigenous girls' presencing as decolonizing force. Girlhood Studies, 7(1), 8-26. doi:10.3167/ghs.2014.070103

Depelteau, J., \& Giroux, D. (2015). LGBTQ issues as Indigenous politics: Two-Spirit mobilization in Canada. In M. Tremblay (Ed.), Queer moblizations: Social movement activism and Canadian public policy ( $1^{\text {st }}$ ed., pp. 64-94). University of British Columbia Press.

Driskill, Q.-L. (2010). Doubleweaving two-spirit critiques: Building alliances between native and queer studies. GLQ: A Journal of Lesbian and Gay Studies, 16(1-2), 69-92. doi:10.1215/10642684-2009-013

Driskill, Q.-L., Finley, D., Gilley, B. J., and Morgensen, S. L. (Eds.). (2011). Queer Indigenous studies: Critical interventions in theory, politics and literature. University of Arizona Press.

Fieland, K. C., Walters, K. L., \& Simoni, J. M. (2007). Determinants of health among two-spirit American Indians and Alaska Natives. In I. H. Meyer \& M. E. Northridge (Eds.), The health of sexual minorities (pp. 268-300). Springer Science + Business Media. doi:10.1007/978-0$\underline{387-31334-4 \_11}$

Green, J. (Ed.). (2007). Making space for Indigenous feminism. Fernwood Publishing. 
International Journal of Child, Youth and Family Studies (2021) 12(3/4): 74-103

Hunt, S. (2016). An introduction to the health of two-spirit people: Historical, contemporary and emergent issues. National Collaborating Centre for Aboriginal Health. https://www.ccnsanccah.ca/docs/emerging/RPT-HealthTwoSpirit-Hunt-EN.pdf

Hunt, S. (2018). Embodying self-determination: Beyond the gender binary. In M. Greenwood, S. de Leeuw, \& N. M. Lindsay (Eds.), Determinants of Indigenous peoples' health: Beyond the social (2nd ed; Ch. 3.). Canadian Scholars' Press.

Hunt, S., \& Holmes, C. (2015). Everyday decolonization: Living a decolonizing queer politics. Journal of Lesbian Studies, 19(2), 154-172. doi:10.1080/10894160.2015.970975

Kirmayer, L., Simpson, C., \& Cargo, M. (2003). Healing traditions: Culture, community, and mental health promotion with Canadian Aboriginal peoples. Australasian Psychiatry, 11,1523. doi:10.1046/j.1038-5282.2003.02010.x

Laing, M. (2018). Conversations with young two-spirit, trans and queer Indigenous people about the term two-spirit [Doctoral dissertation, University of Toronto]. https://tspace.library.utoronto.ca/handle/1807/91455

Lavallee, L. F., \& Poole, J. M. (2010). Beyond recovery: Colonization, health and healing for Indigenous people in Canada. International Journal of Mental Health and Addiction, 8(2), 271-281. doi:10.1007/s11469-009-9239-8

McLeod, A. (2017). Spirituality in the 90s and the day a red-tailed hawk feather fell to earth. Red Rising Magazine, 7, 5-7.

Monture-Angus, P., \& Stiegelbauer, S. M. (1996). Thunder in my soul: A Mohawk woman speaks. Resources for Feminist Research, 25(1/2), 52.

http://myaccess.library.utoronto.ca/login?qurl=https $\% 3 \mathrm{~A} \% 2 \mathrm{~F} \% 2 \mathrm{Fwww}$.proquest.com $\% 2 \mathrm{Fsch}$ olarly-journals\%2Fthunder-my-soul-mohawk-womanspeaks \%2Fdocview\%2F194880424\%2Fse-2\%3Faccountid\%3D 14771

Muñoz, J. E. (2009). Cruising utopia: The then and there of queer futurity. New York University Press.

Simpson, L. (2012). Queering resurgence: Taking on heteropatriarchy in Indigenous nation building [Blog]. Mamawipawin: Centre for Indigenous Governance \& Community Based Research. https://blogs.cc.umanitoba.ca/mamawipawin/2012/06/01/queering-resurgencetaking-on-heteropatriarchy-in-indigenous-nation-building/

Simpson, L. B. (2015). The place where we all live and work together: A gendered analysis of "sovereignty". In S. N. Teves, A. Smith, \& M. H. Raheja (Eds.), Native studies keywords (pp.18-24). University of Arizona Press. 
International Journal of Child, Youth and Family Studies (2021) 12(3/4): 74-103

Simpson, L. B. (2017). Kwe as resurgence method. In L. B. Simpson, As we have always done: Indigenous freedom through radical resistance (pp. 27-38). University of Minnesota Press.

Snowshoe, A., Crooks, C. V., Tremblay, P. F., \& Hinson, R. E. (2017). Cultural connectedness and its relation to mental wellness for First Nations youth. Journal of Primary Prevention, 38 , 67-86. doi:10.1007/s10935-016-0454-3

St. Denis, V. (2007). Feminism is for everybody: Aboriginal women, feminism, \& diversity. In J. Green (Ed.), Making space for Indigenous feminism (pp. 33-52). Fernwood Publishing.

Teengs, D., \& Travers, R. (2006) "River of life, rapids of change": Understanding HIV vulnerability among two-spirit youth who migrate to Toronto. Health Sciences Faculty Publications. https://scholars.wlu.ca/hesc_faculty/2

Tuck, E. (2009). Suspending damage: A letter to communities. Harvard Educational Review, 79(3), 409-428. doi:10.17763/haer.79.3.n0016675661t3n15

Walters, K. L., Evans-Campbell, T., Simoni, J. M., Ronquillo, T., \& Bhuyan, R. (2006). “My spirit in my heart": Identity experiences and challenges among American Indian two-spirit women. Journal of Lesbian Studies, 10(1-2), 125-149. doi:10.1300/J155v10n01 07

Wesley, D. L. (2015). Reimagining two-spirit community: Critically centering narratives of urban two-spirit youth [Master's thesis, Queens University]. https://qspace.library.queensu.ca/bitstream/handle/1974/13024/Wesley_Dana_L_201504_MA .pdf? sequence $=1 \&$ is Allowed $=y$

Wexler, L. (2014). Looking across three generations of Alaska Natives to explore how culture fosters Indigenous resilience. Transcultural Psychiatry, 51(1), 73-92. doi:10.1177/1363461513497417

Whitehead, J. (2017). full metal indigiqueer. Talon Books.

Whitehead, J. (2018, December 31). Why Joshua Whitehead explores being Indigiqueer and twospirit in his debut novel. The Next Chapter, CBC Radio.

https://www.cbc.ca/radio/thenextchapter/full-episode-dec-31-2018-1.4956361/why-joshuawhitehead-explores-being-indigiqueer-and-two-spirit-in-his-debut-novel-1.4956994

Wilson, A. (1996). How we find ourselves: Identity development and two-spirit people. Harvard Educational Review, 66(2), 303-317. https:/www.hepg.org/her-home/issues/harvardeducational-review-volume-66-issue-2/herarticle/identity-development-and-two-spiritpeople_278

Wilson, A. (2008). N'tacimowin innan nah': Our coming in stories. In P. A. Monture \& P. D. McGuire (Eds.), First voices: An Aboriginal women's reader. Inanna Publications.

Wilson, A. (2015). Our coming in stories: Cree identity, body sovereignty and gender selfdetermination. Journal of Global Indigeneity, 1(1), 4. https://ro.uow.edu.au/jgi/vol1/iss 1/4 